\title{
Develop Education for the Elderly in the Context of Rural Revitalization Strategy and Improve Rural Elderly Care
}

\author{
Shuang liu ${ }^{1}$, Xiaofeng Cong ${ }^{2}$, Xiaojie Gong ${ }^{3}$, Jia cong* \\ 1,2,3 Institute of political science and law, University of jinan,Shandong 250022,China \\ * Lancaster University The United Kingdom, Ph.D. Email: 2428407729@qq.com
}

\begin{abstract}
In recent years, the aging of the population has become more and more serious, which has become a major obstacle to my country's economic and social development, and has caused a series of pension problems. How to better realize the "elderly support and support" of the rural elderly has become an important social issue. Education for the elderly is an important way to solve the low quality of the elderly population. With the implementation of the rural revitalization strategy, rural development has undergone new changes. The proposal of the rural revitalization plan in 2018 has pushed a new round of rural pension plans to a new stage[1], actively promoting community education for the elderly is of great significance to improving the lifelong education system. This article first explains the importance of community education for the elderly, under the background of carrying out lifelong education in our country, there are deficiencies in understanding and development in community elderly education. Thus combined with the actual national conditions of our country, it elaborated on the integration of education resources for the elderly, the establishment of a sound education management mechanism for the elderly, and the promotion of the development of educational diversification.
\end{abstract}

Keywords: Aging population, Revitalization of rural industries, Education for the elderly

\section{INTRODUCTION}

\subsection{The status quo of rural elderly care in my country}

The aging of the population has now become an important national condition in my country. According to relevant data released by the National Bureau of Statistics, as of the end of 2018, the total number of people over 60 in my country is about 250 million[2]. In the nationwide "silver wave", due to the outflow of young and middle-aged labor from rural areas and the imbalance in the development of urban and rural elderly care services, the situation of rural aging is particularly severe, with characteristics such as "getting old before getting rich" and "aging before getting rich" stand out. Rural old-age care is the shortcoming of my country's old-age care, but it is also the key to promoting the progress of my country's old-age care. It is directly related to the stability of Chinese rural areas and the sustainable development of agriculture. With the increasing degree of aging in my country, based on the characteristics of the uneven development of aging between urban and rural areas, rural areas have become the focus and difficulty of Chinese response to the challenges of elderly care[3].

In the process of my country's urbanization construction, the urban-rural development gap under the dual economic system of urban and rural areas is obvious. A large number of young and middle-aged laborers in rural areas have migrated to cities, resulting in the proportion of rural elderly being far higher than the national average. Compared with urban areas, the traditional old-age care concept still exists in my country's rural areas, and the rural old-age care system and social security are still incomplete, all of which have brought difficulties for the elderly in rural areas[4].

The traditional family pension in rural areas is facing challenges and its functions are weakening[5][6]:(1) With the acceleration of urbanization, more and more young people are entering cities to work, resulting in the actual proportion of the elderly in rural areas that is 
much larger than the statistics.(2) The family structure is becoming smaller and more core[7], which makes the proportion of children's pensions decline. These are a huge challenge to the traditional rural concepts of "raising children for the elderly" and "multiple children, more blessings".

These are a huge challenge to the traditional rural concepts of "raising children for the elderly" and "multiple children, more blessings".

\subsection{Rural industry revitalization strategy}

In order to solve the rural problems in our country, my country has promulgated the "Strategic Plan for Rural Revitalization (2018-2022)", pushing a new round of rural revitalization plans to a new stage. The report of the 19th National Congress of the Communist Party of China put forward the implementation of the strategy of rural revitalization, and took "prosperous industries, livable ecology, civilized rural customs, effective governance, and prosperous life" as the overall goals of development, of which industrial prosperity is the focus. At the same time, the Central Document No. 1 in recent years has repeatedly emphasized the need to promote the integrated development of rural primary, secondary and tertiary industries, forming leisure tourism, catering and homestays, cultural experience, health and wellness, and elderly services that meet the needs of urban and rural residents, and strive to build agriculture and the modern industrial system of the cross integration of the secondary and tertiary industries.And industrial integration has become the core concept of promoting the development of rural industries in the new era. The Fourth Plenary Session of the 19th Central Committee of the Communist Party of China pointed out that to implement the strategy of rural revitalization, it is necessary to improve the system and policies that give priority to the development of agriculture and rural areas and ensure national food security, and at the same time improve the care and service system for left-behind children, women and the elderly in rural areas. These policies provide a realistic basis and policy conditions for the development of rural agriculture and the development of rural pension industries.

\section{3 "Industry to promote the aged" based on the revitalization of rural industries}

Anthony Giddens proposed the inter-embedding relationship between the system and the actors in his discourse on the interaction between the system and the actors, He believes that people can influence social systems through actions, and in turn systems can also promote people's actions[8]. It can be seen that under the country's rural revitalization strategy, rural industries have been developed and the living conditions of rural elderly people have also been changed, which has improved the rural elderly care status.

\section{ACHIEVEMENTS IN RURAL ELDERLY CARE UNDER THE BACKGROUND OF RURAL INDUSTRY REVITALIZATION}

The development of rural elderly care requires rational planning of the urban-rural development layout structure, strengthens the leading role of urban areas in rural areas, and enhances the integration of rural elderly care services with urban elderly care services. At the same time, it is necessary to use the comparative advantages of rural areas to develop rural elderly care models. With the implementation of my country's rural revitalization strategy, some rural industries have achieved better development, and some achievements have been made in rural pensions.

The revitalization of rural industries and the development of agricultural economy on their own land provide a carrier for the rural elderly to maintain their inherent production and lifestyle.Affected by traditional thinking, most rural elderly people are unwilling to be separated from their living environment. At the same time, the long-term relationship network and living habits have also prompted them to choose to live in rural areas.The development of the village's agriculture provides a carrier for maintaining the inherent production and lifestyle. For the elderly, it also provides the possibility and support for them to provide for the elderly on the spot. As for the young people, agriculture can not only ensure that the elderly farmers obtain certain economic benefits and alleviate the financial burden of the family, but also provide them with places and opportunities to use the waste heat, strengthen their confidence in agricultural production, and promote the elderly. Realization of doing something, relying on the old, and having fun in the old.

With the revitalization of rural industries and the development of the overall rural economy, more livelihood security has increased the enthusiasm of the elderly to participate in social activities and enriched the spiritual and cultural life of the elderly. The mental health level of the rural elderly in my country is lower than that of the urban elderly and ordinary elderly, and the characteristics of vulnerability and vulnerability are obvious[9]. Individual factors such as gender, marriage, education level, socio-economic status, and physical health have a significant impact on the mentality of the elderly[10]. At the same time as the revitalization of rural industries, some villages have established libraries, happiness homes for the elderly, and leisure and entertainment squares for the elderly. Elderly people over the age of 70 can eat for free, and some needy elderly people can enjoy the annual subsidy distributed in the village. The elderly have a higher evaluation of 
their own lives, which significantly improves the mental health of the elderly and their living conditions.

\section{PROBLEMS STILL EXISTED IN RURAL OLD-AGE CARE UNDER THE BACKGROUND OF RURAL INDUSTRY REVITALIZATION}

At present, in the context of the rural revitalization strategy, the achievements of rural elderly care are obvious, but the challenges are also huge. In the context of the rural revitalization strategy, rural elderly care still faces many challenges: First, the needs of rural elderly care cannot be well met, such as the care of disabled elderly and day care issues, which obviously shows the shortage of elderly service personnel. Second, what exactly are the needs of the elderly in rural areas for elderly care services, and what kind of elderly care services should be developed, need to be further clarified. Third, the current development of the rural agricultural industry economy does not allow the village to establish an elderly care institution that can provide residential and care services. The rural family pension is still the main solution to the rural aging. In the face of many problems in rural elderly care, relevant researchers have pointed out that the way out for rural elderly care in China lies in the development of mutual assistance in rural elderly care. Mutual assistance for the elderly based on the village acquaintance society and family-based elderly care provides China with a low-cost, high-quality elderly care model, and provides a strategic choice for China to cope with aging, Professor Xuefeng He believes. And how to explore how to implement mutual assistance for the elderly in the context of the positive development of the rural industry is also a major problem.

\section{THE CHALLENGE OF IMPROVING MY COUNTRY'S RURAL ELDERLY SERVICE UNDER THE BACKGROUND OF RURAL REVITALIZATION STRATEGY}

The implementation of the rural revitalization strategy is an opportunity for my country's rural development, but there are still many challenges in the implementation process, which need to be improved from the following aspects.

\subsection{Old people in rural areas are backward}

Backwardness has always been one of the major issues that plagued the development of rural elderly care in our country, In rural areas of our country, family care for the elderly has always been a mode of care for the elderly mainly relied on. Most rural social security departments did not recognize the challenges faced by the aging population in rural areas, and the community's awareness of providing for the elderly was weak. In addition, the living standard of rural residents is low and their own education level is low, their ideas can't keep up with the times and still stay at the traditional level. On the issue of old-age care, the acceptance of new old-age care concepts is weak, unable to fully understand the old-age care services of the new generation, and hesitant to accept the new old-age care model.Even with the implementation of the rural revitalization strategy, the problem of changing the concept of rural residents is still one of the factors hindering development.

\subsection{Insufficient young people to revitalize rural industries}

The improvement of rural elderly care services is inseparable from young talents. If the rural industry and rural elderly care services are to continue to develop continuously, a group of young and middle-aged talents must be supported as backbone forces. However , due to the backwardness of the rural economy and lack of employment opportunities, the loss of young and middle-aged talents is still a problem that needs to be faced in order to attract a large number of young and middle-aged talents in rural areas to the revitalization of rural industries.

\subsection{Inaccurate industry positioning and insufficient continuous industry development}

The rural revitalization strategy provides policy support for rural development in my country and is an opportunity to improve the overall living conditions in my country's rural areas. However, how to find the most suitable industry for one's own village to achieve sustainable village production has become a problem that plagues the development of villages.

\subsection{Unclear development concept}

The development concept has not been fully integrated into the active aging thinking. The issues of why development, what services to develop, and who will develop it, need to be further clarified. It is not clear what exactly are the needs of the elderly in rural areas and what kind of elderly care services should be developed.

\subsection{Issues left over from history}

The rural elderly care service system has historically owed too many debts, and the actual task is huge. Due to the late start of socialized elderly care services in rural areas, whether it is elderly care facilities, service personnel, social organizations, etc., rural areas are seriously lagging behind cities. In addition, rural 
elderly people generally face risks such as poverty, health, care, and social security. In contrast, the task of building the rural elderly care service system is particularly huge.

\subsection{Problems in the implementation of the rural revitalization strategy}

The rural revitalization strategy is still imperfect in the layout of the service system construction, and the favorable factors mentioned are seriously fragmented. Although the strategic plan proposes to build a rural elderly care service system, it also mentions the required facilities, personnel, social organization, and technical elements, but they are scattered in various parts, and there is no unified plan. Therefore, how to fragment these The integration of favorable factors into the guiding opinions for promoting the construction of the system requires greater efforts.

\section{CONCLUSION}

As a huge group in our country, the rural elderly group has made a great contribution to the prosperity of society. The economic development of the society has inherited the results. They have the right to live a dignified and secure life in their later years. In 2000, China has entered an aging society. Faced with the fact that empty nest families are rising, it has effectively optimized rural elderly care and provided multiple services for rural elderly people. And try to respond to their different needs, so that they have an appropriate position and role in the village, and have a rich and worry-free old age is one of the problems that the country has been trying to solve. Chinese rural revitalization strategy provides good infrastructure conditions for rural elderly care, and can also provide adequate resource support. Village construction has lubricated the elderly care technology. At this stage, my country's rural areas should seize the opportunity of rural industry revitalization, actively develop advantageous industries in the village, and take industrial economic development as the priority principle to improve the rural elderly care system and improve the current situation of rural elderly care.

Improving the rural elderly care service system is the inherent task of implementing the rural revitalization strategy, and it is an inevitable requirement for rural people to share the fruits of development.

Under the background of the rural revitalization strategy, realize the rural industry cycle, gradually get rid of the substantial dependence on government finance under the premise of government policy support, and explore the path of healthy development in rural areas, so as to improve the current situation of rural elderly care services and realize the rural elderly care service system Optimize and improve.

\section{REFERENCES}

[1] Zhang Haipeng, Gao Liangliang, Yan Kun, The theoretical origin, main innovation and realization path of rural revitalization strategic thinking, China Rural Economy, 2018(11): 2-16. DOI:CNKI: SUN:ZNJJ.0.2018-11-001.

[2] 2018 National Economic and Social Development Statistical Bulletin. National Bureau of Statistics: http://www.stats.gov.cn.DOI:CNKI:SUN:CSGT.0. 2019-06-021.

[3] Du Peng, The status quo and development direction of rural elderly care services in China. Social Work in China, 2018, (26): 27. DOI:10.3969/j.issn. 1674-3857.2018.26.014.

[4] Shi Jinyu, The predicament of the elderly in rural empty-nest elderly under the new urbanization. Agricultural Economics, 2020, (6):87.DOI: CNKI:SUN NYJJ.0.2020-06-033.

[5] Liu Xudong,Pei Xia, Research on the life welfare of rural elderly women. China Collective EconomySocial Vision, 2009(1): 196-197.DOI: 10.3969/ j.issn. 1008-1283.2009.10.103.

[6] Si Qiong, A Brief Analysis of my country's Rural Pension Insurance System[J].Three Rural Issues, 2009,(6):221.DOI:CNKI:SUN:SYWX.0.2009-06-1 83.

[7] Chen Shaoping,Chen Shamai, The status quo and thinking of the rural elderly care in China.Journal of Fujian Agriculture and Forestry University, 2002,5(1):13-16.DOI:10.3969/j.issn.1671-6922.20 02.01.003.

[8] Anthony Giddens, The Constitution of Society[M], translated by $\mathrm{Li}$ Kang and $\mathrm{Li}$ Meng, Beijing: Sanlian Bookstore, 1998:80.ISBN: 7-108-01142-5.

[9] Li Deming, Chen Tianyong, Wu Zhenyun, The quality of life and subjective well-being of the elderly in rural China.Chinese Journal of Gerontology,2007,(12):1194.DOI:CNKI:SUN:ZLX Z.0.2007-12-036.

[10] Tang Dan, The Moderating Effect of Urban and Rural Factors in the Model of Depressive Symptoms in the Elderly, Population Research, 2010,(3):56.DOI:CNKI:SUN:RKYZ.0.2010-03-00 6. 